\title{
El fomento crediticio a los grupos económicos en la industrialización sustitutiva de importaciones chilena (1939-1970)
}

\section{The Credit Promotion to the Business Groups in Chilean Import Substitution Industrialization (1939-1970)}

\author{
Andrés Aguirre $^{1, *}$ (D) 0000-0001-5919-7790
}

${ }^{1}$ Universitat de Barcelona, Barcelona, España.

*Correspondencia: andresaguirreb@hotmail.com

Resumen. En un mercado de capitales prácticamente inexistente en cuanto a créditos de largo plazo, el Estado proveerá de financiamiento crediticio de manera directa e indirecta, mediante crédito externo y doméstico, a importantes unidades pertenecientes a grupos económicos del país. A través de fuentes institucionales y empresariales, se analiza el alcance de las medidas de fomento interpuestas por el Estado chileno en relación con los grupos empresariales en la industrialización sustantiva de importaciones.

Palabras clave: crédito; industrialización sustitutiva; importaciones; grupos económicos; fomento.

Abstract. In a capital market practically non-existent in of long-term credits, the State will provide credit financing directly and indirectly, through foreign and domestic credit, to important units belonging to the main economic groups of the country. Through institutional and companies sources, it's how analyzed the scope of the measures interposed by the Chilean State in relation to business groups in the import substitution industrialization.

CÓMO CITAR: Aguirre, A. (2020). El fomento crediticio a los grupos económicos en la industrialización sustitutiva de importaciones chilena (1939-1970). América Latina en la Historia Económica, 27(3), e1039. doi: 10.18232/alhe.1039 
Aguirre, A. / El fomento crediticio a los grupos económicos en la industrialización sustitutiva de importaciones chilena (1939-1970)

Key words: import; substitution industrialization; economic groups; credit; promotion.

JEL: N16.

Recibido: 25 de noviembre de 2018

Aceptado: 17 de mayo de 2019

Publicado: 21 de julio de 2020.

\section{INTRODUCCIÓN.}

La industrialización sustitutiva de importaciones (en adelante IsI) fue el esquema de desarrollo económico imperante en América Latina entre la posguerra de la segunda guerra mundial y la crisis de la deuda externa de 1982 1 Esta estrategia de industrialización se caracterizó por una significativa participación del Estado en materia de protección comercial, producción, inversión y fomento al sector privado, de tal forma que la isı constituyó un ejemplo canónico en relación con los rasgos constitutivos de este modelo económico ${ }^{2} \mathrm{Si}$ bien las directrices y resultados de la IsI chilena han sido tratados de manera extensa, aún faltan aportaciones que analicen las funciones del Estado en relación con los grupos económicos y grandes empresas en el marco del esquema industrializador 3

En este artículo se examinan las características y resultados del fomento crediticio a los grupos económicos efectuado por el Estado chileno a través de la Corporación de Fomento de la Producción (en adelante CORFo o Corporación) entre 1939 y 1970, aspecto de la industrialización sustitutiva de importaciones hasta el momento inexplorado. Además de presentar información sobre los créditos recibidos por grandes empresas no afiliadas. Este trabajo profundiza en el fomento crediticio a los grupos empresariales receptores de los apoyos directos e indirectos canalizados por CORFO, controladores de las mayores empresas privadas de capital nacional en el periodo.

\footnotetext{
${ }^{1}$ Siguiendo la periodización en torno a la ISI, fechada entre 1939 y 1973, suele incorporarse al gobierno de la Unidad Popular, 1970-1973, en las postrimerías del modelo industrializador (Ffrench-Davis, 2008; Meller, 2007). Dada la excepcionalidad de las medidas del gobierno socialista caracterizadas por la transferencia de la gran propiedad privada al Estado mediante la formación del Área de Propiedad Social, a efectos de esta contribución nos circunscribimos al periodo 1939-1970.

${ }^{2}$ Acerca de la ISI en América Latina, véanse Bethell (1994), Bulmer-Thomas (1998), Fajnzylber (1983), Haggard (1990), Hirschman (1981), Hofman (2000) y Prebisch (1981). Este modelo de industrialización también será implementado en Europa meridional, Turquía e India (Amsden,2001). Acerca de los grupos económicos en el escenario de la ISI en Chile, véanse Paredes y Sánchez (1996), Salvaj y Couyoumdjian (2016) y Zeitlin y Ratcliff (1988). Sobre los grupos en América latina, véanse Fernández, Lluch y Barbero (2015) y Jones y Lluch (2011).

${ }^{3}$ Un grupo económico se constituye como una matriz controladora de un conjunto de empresas que operan en diversos mercados. Después de analizar a los grupos señalados en Lagos (1960) y Garretón y Cisternas (1970), determinamos la presencia de ocho grandes grupos económicos existentes en Chile durante la IsI, vinculados a una familia como núcleo controlador: Matte, Edwards, Menéndez y Braun, Cousiño, Cosatán, Yarur, Said y Claude. A los cuales se añaden desde mediados de la década de 1950, los grupos Angelini y Luksic, y a partir de la década de los sesenta, Banco Hipotecario de Chile. A excepción de este último, en adelante los grupos se mencionan por el nombre de la familia controladora.
} 
Aguirre, A. / El fomento crediticio a los grupos económicos en la industrialización sustitutiva de importaciones chilena (1939-1970)

En el primer apartado se presentan los lineamientos fundamentales de la isi y el mercado de capitales en el periodo de estudio. Más adelante, se desarrollan las características y resultados de la provisión de crédito directo e indirecto efectuada por el Estado chileno a través de corfo; por último, se determina el alcance de las medidas de fomento crediticio a los grupos económicos en el escenario de la ISI.

\section{LA INDUSTRIALIZACIÓN SUSTITUTIVA DE IMPORTACIONES: EL MERCADO DE CAPITALES COMO ESCENARIOS DEL FOMENTO CREDITICIO.}

El origen de la ISI en América Latina se relaciona con el abrupto descenso experimentado por la demanda de commodities, resultado de la crisis internacional de 1929. En este marco, la estrategia exportadora de productos primarios como fuente de crecimiento y captación de divisas por parte de los países latinoamericanos experimentó una profunda crisis (Bértola y Ocampo, 2013; Ocampo, Cárdenas y Thorp, 2003).4 En Chile, las repercusiones de la Gran Depresión se prolongaron hasta finales de la década de 1930. Este acontecimiento impulsó la transición desde un esquema abocado a la exportación de materias primas concentradas en salitre y cobre 5 a una estrategia de desarrollo económico del mercado interno sustentado en la protección comercial y la expansión de la manufactura $4^{6}$ Con la fundación de CORFo, el 29 de abril de 1939, durante el gobierno del radical Pedro Aguirre Cerda, se reúnen las visiones políticas y técnicas en torno a la necesidad de instaurar un modelo económico protagonizado por un Estado activo en el proceso de acumulación y orientación general de la economía, conformando así la economía mixta con la mayor presencia económica del Estado en Latinoamérica.7 7 La creación de coRfo supuso la articulación del denominado Estado de compromiso, en donde los partidos representativos de las clases empresarial, media, y laboral acordaron el respeto a las reglas del juego democrático para la implementación del proceso de desarrollo económico. Debido a la presión de los grupos oligárquicos se excluyó de este acuerdo de gobernanza política la realización de una reforma agraria que redistribuya la propiedad. Así, de manera conjunta con la participación de la burocracia estatal, profesional y de los trabajadores urbanos, la coalición social que impulsó la creación de corfo contó con el respaldo del gran empresariado industrial a través de sus organizaciones de intereses aglutinadas en la

\footnotetext{
${ }^{4}$ Recientemente, Bértola y Ocampo (2013) acuñan el término Industrialización dirigida por el Estado para referirse al periodo en que se enmarca la ISI. En este sentido, si bien coincidimos en la relevancia del Estado para llevar a cabo la industrialización, se corre el riesgo de subvalorar el papel del empresariado industrial en la demanda por protección comercial y fomento al Estado, así como también soslayar la presencia de este sector en los órganos rectores del proceso. De este modo, se opta por utilizar la denominación habitual de este esquema de desarrollo económico. En relación con la actuación del gran empresariado y sus sectores políticos afines en la orientación económica del país durante la ISI, véanse Casanova (2018) y Cavarozzi (2017).

${ }^{5} \mathrm{El}$ cobre, principal producto de exportación chileno, representó, en promedio el $19 \%$ de la recaudación fiscal a lo largo de la IsI, (Meller, 2007).

${ }^{6}$ Durante la ISI se consolidó una robusta protección comercial a la producción manufacturera tanto de carácter arancelario como por intermedio de cuotas y prohibiciones a la importación (Ffrench-Davis, 2008; Muñoz, 1968). La manufactura como porcentaje del PIB en 1940 representó $12.2 \%$. En 1970 la participación de la industria manufacturera en el producto alcanzará a un $23.5 \%$ (Díaz, Lüders y Wagner, 2016).

${ }^{7}$ Acerca de la formación de corfo, véanse Casanova (2018), Cavarozzi (2017) y Ortega (1989). Sobre las funciones económicas del Estado chileno durante la IsI, véanse Ffrench-Davis (2008), Mamalakis (1976) y Sunkel (2011).
} 
Sociedad de Fomento Fabril.$^{8}$ La presencia de los sectores propietarios (industrial, minera, agrícola y comercial) se reflejó en la conformación del Consejo de la coRfo, liderado por el ministro de Economía, el vicepresidente ejecutivo de la entidad y los consejeros conformados por: cinco representantes del presidente de la República; cuatro representantes del parlamento (dos elegidos por acuerdo de la Cámara de Diputados y dos por el Senado); un representante de cada gremio patronal de entidades como la Sociedad de Fomento Fabril, la Sociedad Nacional de Agricultura, la Sociedad Nacional de Minería y la Cámara de Comercio de Chile; un representante del Instituto de Ingenieros; un representante de los organismos de crédito sectoriales vinculados con la pequeña y mediana empresa (industrial, minero, agrícola e hipotecario, todos absorbidos por la formación del Banco del Estado en 1953), y un representante de la principal organización de trabajadores. Esta estructura se mantuvo en lo fundamental, con la excepción señalada para los organismos crediticios, a lo largo de la ISI (CORFo, 1949, 1954; Ortega, 1989).

La IsI se diferenció en dos fases sucesivas relacionadas con las exigencias del proceso de industrialización. En la primera etapa, conocida como de sustitución fácil, se reemplazaron las importaciones de bienes de consumo no durables e intermedios por producción doméstica. La segunda, sustitución difícil de importaciones, es la fase madura del proceso en donde se promovió la producción nacional en los mercados de consumo durables, así como el segmento de bienes de capital

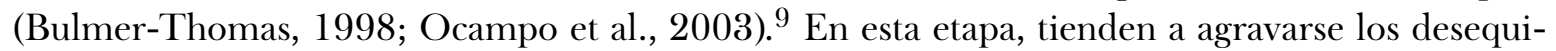
librios económicos relacionados con las exigencias de la industrialización en economías proclives al déficit público y al deterioro de la balanza de pagos. En América Latina, la vigencia de la Isi se extendió hasta mediados de la década de los setenta y la crisis de la deuda externa de 1982.

En la década de los cincuenta, es amplio el nivel de sustitución de importaciones alcanzado en determinadas ramas industriales, sobre todo en la culminación de la etapa fácil de la isi (véase cuadro 1). En el sector de bienes de consumo no durable, los rubros de calzado, tabaco y bebidas se encuentran prácticamente sustituidos con anterioridad a la instauración de la ISI (Muñoz, 1968). En el rubro de alimentos (bebidas, azúcar y aceites), se desempeña el grupo Edwards, controlador de importantes unidades monopólicas orientadas al mercado interno como la Compañía Refinería de Azúcar Viña del Mar y la Compañía Cervecerías Unidas. Por otro lado, grupos textiles como Yarur y Said se posicionaron en un segmento que a inicios de la década de los cincuenta cubrió con producción doméstica el mercado. Yarur dirige la principal unidad textil del país: Yarur Hermanos, llamada desde la década de los sesenta Manufacturas Chilenas de Algodón, S. A.

En consonancia con la diversificación de la economía y las fases de crecimiento económico -con importantes fluctuaciones a nivel agregado-, junto con la mejora del poder adquisitivo de la población, se realizaron grandes inversiones que dieron curso a las infraestructuras y empresas estatales en la producción de bienes intermedios e intensivos de capital en segmentos como el acero y la energía eléctrica, así como la cobertura de la demanda interna de bienes de consumo no durable (alimentos procesados, calzado, y vestuario) e intermedios como el papel y el segmento textil. El

\footnotetext{
${ }^{8}$ La Sociedad de Fomento Fabril es el organismo que reúne al gran empresariado industrial, fundada en 1883. Un texto ilustrativo respecto a la demanda de protección comercial por parte del gran empresariado se encuentra en Jaramillo, Müller, Izquierdo y Simón (1939). Sobre el apoyo de los gremios empresariales para la conformación de la ISI, véase Ibáñez (1994). Acerca de las relaciones entre el empresariado y el Estado durante el modelo industrializador, véanse Montero (1997) y Pinto (1986). Respecto al sistema de coaliciones sociales en que se sustenta la industrialización sustitutiva de importaciones, véase Silva (2007).

${ }^{9}$ A este respecto, Bértola y Ocampo (2013) también distinguen dos fases del proceso de industrialización a las cuales denominan clásica y madura.
} 
Aguirre, A. / El fomento crediticio a los grupos económicos en la industrialización sustitutiva de importaciones chilena (1939-1970)

\section{CUADRO 1. SUSTITUCIÓN DE IMPORTACIONES EN RAMAS DEL SECTOR MANUFACTURERO A MEDIADOS DE LA DÉCADA DE 1950. DIFERENCIA ENTRE AMBOS PERIODOS, EN PORCENTAJES}

\begin{tabular}{lr}
\hline \multicolumn{1}{c}{ Ramas industriales } & $1925-1929$, \\
$1948-1952$ \\
\hline Acero y hierro & $-66^{\mathrm{a}}$ \\
Hilados, textil & -78 \\
Metalurgia & -21 \\
Celulosa y papel & -12 \\
Vidrio & -65 \\
Maderero & -79 \\
Cueros & -78 \\
Aceites & -79 \\
Diversos & -80 \\
\hline
\end{tabular}

a Cifra correspondiente a los periodos $1925-1929$ y 1951-1955.

Fuente: elaboración propia con base en Sociedad de Fomento Fabril (1963) y Pinto (1959).

dinamismo económico y la evolución del PIB comienzan a experimentar signos de agotamiento a mediados de la década de los cincuenta. Asimismo, se apreció un incremento de la inflación profundizado desde 1953, con un alza del nivel de precios que transita desde $12 \%$ en 1952 a $56 \%$ en el siguiente año. Los eventos inflacionarios se agudizarán en 1954 con $71.1 \%$ y en 1955 con 83.1\%, máximo histórico hasta la crisis político-económica de 1972-1973 10 A lo largo de la ISI, la inflación se posicionará en dos dígitos unida a la persistencia de una tasa de interés real negativa, cuestión que redundará en la escasez de crédito de largo plazo provisto por el sector privado 11

Posterior a la firma del acuerdo de Bretton-Woods en $1944 \sqrt{12}$ y hasta la segunda mitad de la década de los setenta, el sistema financiero internacional se rigió por un esquema de represión financiera (Díaz-Alejandro, 1985; McKinnon, 1980). En este modelo existió una activa presencia estatal: los gobiernos regularon de manera efectiva el mercado financiero y de capitales, y controlaron variables clave como la tasa de interés y gran parte de la provisión del crédito destinado a las políticas y planes de desarrollo económico. Chile no fue ajeno a esta característica. El Estado desempeñó una función relevante en el sistema bancario a través de la fijación de la tasa de interés máxima convencional y la aplicación de altos encajes a la banca comercial, lo que redujo el margen de intermediación y el control de las colocaciones bancarias. Desde 1953 el Banco Central añadió prestaciones crediticias a sus funciones monetarias. El Estado mantuvo el control de la cuenta de

\footnotetext{
${ }^{10}$ Sobre las determinantes de la inflación en Chile, véanse Ffrench-Davis (2008), Landerretche (1983), Mamalakis (1976), Muñoz (1995), Pinto (1959; 1964) y Sunkel (2011). En promedio, la inversión durante la IsI se sitúa en $11.9 \%$ (CORFo, 1966b; Díaz, Lüders y Wagner, 2010).

${ }^{11}$ Este es uno de los rasgos comunes a las economías involucradas en la aplicación del modelo IsI. En Chile, durante la ISI, la presencia de una tasa de interés real negativa es prácticamente constante a excepción de la primera mitad de la década de 1940 y el bienio 1960-1961 con motivo de la reducción de la inflación mediante un programa de austeridad llevado a cabo en el mandato de Alessandri Rodríguez, 1958-1964.

${ }^{12}$ Sobre la función de las instituciones de crédito internacional en esta materia, véanse Kindleberger (1992), Marichal (2010) y Reinhart y Rogoff (2011);
} 
capitales, y en un contexto inflacionario, estableció la exclusión de las entidades financieras privadas de la disponibilidad de instrumentos reajustables. Por otro lado, a lo largo del proceso de industrialización, el mercado de capitales chileno operó con una tasa de interés inferior a la inflación anual. De acuerdo con Jeftanovic (1961) esta característica condujo a un paulatino deterioro de las utilidades bancarias. La volatilidad que exhibió la inflación contribuyó a desincentivar la disponibilidad de mecanismos crediticios de largo plazo. Los activos empresariales no disfrutaron de corrección monetaria hasta 1965. No obstante, los bonos hipotecarios del Banco del Estado sí fueron reajustables. De este modo, se experimentó un constante descenso en las transacciones bursátiles y la virtual desaparición de los bonos de empresas y obligaciones como objeto de inversión (Jeftanovic, 1979). A raíz del deterioro de la Bolsa como fuente de recursos, las grandes empresas del país aminoraron la distribución de utilidades en la forma de dividendos y aumentaron para fines de capitalización el fondo de reservas con vistas a la reinversión de beneficios. Asimismo, recurrieron a la emisión de acciones liberadas para incrementar el capital a costa de aquel fondo 13 Estos rasgos del mercado accionario conducirán a que el precio de los títulos mobiliarios presente de manera habitual un monto inferior al valor contable (Garretón y Cisternas, 1970) 14

En suma, la existencia de un régimen con amplios volúmenes de colocaciones estatales, una regulación abocada a impedir los préstamos relacionados, la persistente inestabilidad del nivel de precios, junto a una tasa de interés real negativa, hizo que la banca privada con presencia predominante de los grupos empresariales se concentrara en la canalización de créditos de corto plazo orientados a cubrir el capital de explotación. Así, según el Instituto de Organización y Administración de Empresas, con base en el único informe sobre el financiamiento de las grandes compañías chilenas durante la ISI, en el periodo 1949-1960, las fuentes de financiamiento fueron las siguientes: $52 \%$ a fuentes internas (utilidades no distribuidas) y $48 \%$ a fuentes externas. De estas últimas, $41 \%$ consistió en préstamos bancarios de corto plazo y sólo $4 \%$ a emisión de acciones. El $3 \%$ restante corresponde a créditos de largo plazo ${ }^{15}$ Lo anterior reafirma la escasa presencia del crédito de largo plazo como fuente de financiamiento para la realización de proyectos de inversión. Además, explica la importancia que adquiere para los grupos de empresas tanto el autofinanciamiento como el control de bancos comerciales para el acceso a créditos de corto plazo computables al fondo del capital de trabajo o explotación. 16

\footnotetext{
${ }^{13}$ Sobre el papel de la inflación en la autofinanciación vía utilidades no distribuidas en la primera fase de la ISI, véase Prados (1956).

${ }^{14}$ Ambos autores subrayan la utilización de la diferencia entre el valor contable y bursátil como un mecanismo clave para el acceso al control de diversas empresas por parte del Banco Hipotecario de Chile. Luego del golpe militar de 1973, se desprenderán de dicho grupo económico los dos grandes conglomerados del monetarismo: Cruzat-Larraín y Vial, esto entre 1974 y la crisis económica de 1982. Acerca de la evolución de largo plazo de los grupos económicos, véase Aguirre (2017).

${ }^{15}$ Instituto de Organización y Administración de Empresas (1962).

${ }^{16}$ Con la excepción del Banco de Chile de propiedad dispersa o managerial, los principales bancos del país durante la ISI son controlados por grupos económicos. Este es el caso del Banco de Crédito e Inversiones (Yarur), Banco Edwards (Edwards), Banco Sudamericano (Matte), Banco Nacional del Trabajo (Angelini), Banco Panamericano (Said), y Banco Hipotecario de Chile.
} 
Aguirre, A. / El fomento crediticio a los grupos económicos en la industrialización sustitutiva de importaciones

LA CORFO Y EL FOMENTO CREDITICIO DE LARGO PLAZO A LOS GRUPOS ECONÓMICOS

Y GRANDES EMPRESAS EN EL TRANSCURSO DE LA ISI.

La conformación de una política de fomento crediticio para la industria chilena se remonta a 1928 con el establecimiento de un sistema orientado únicamente a la pequeña y mediana empresa. En el contexto de las dificultades económicas ocasionadas por el deterioro del mercado internacional del salitre, durante el primer gobierno de Carlos Ibáñez del Campo, de 1927 a1931, se crearon diversos organismos crediticios destinados al sector productivo: Caja de Crédito Minero, en 1927; Caja de Crédito Carbonífero, en 1928, y el Instituto de Crédito Industrial, en 1928. Este último se constituyó como un organismo semipúblico con un financiamiento mayoritariamente privado y con participación estatal (Alessandri, 1935; Kirsch, 1977). Este apoyo a la actividad productiva continuará con Arturo Alessandri -1932 a 1938- y se consolidará a partir de 1939 durante los gobiernos radicales -1939 a 1952- con la creación de CORFo (Ley 6334, 29 de abril de 1939). Durante la ISI chilena, la CORFo se estableció como el organismo responsable del proceso industrializador en el diseño y la ejecución de la política industrial del Estado (CORFo, 1939, 1969). Los objetivos de CORFo se orientaron a elevar el nivel de vida y bienestar de la población, promover el equilibrio y ahorro externo, conformar los planes multisectoriales de desarrollo económico de corto y mediano plazo, establecer el diagnóstico de los recursos y necesidades del país, dirigir la creación de empresas públicas en sectores estratégicos, coordinar las decisiones de fomento crediticio interno y externo, así como la asistencia técnica a la pequeña y mediana empresa. El financiamiento de la CORFo se realizó por intermedio de aporte fiscal mediante tributación, préstamos con cargo al encaje bancario, entradas propias provenientes de amortizaciones y dividendos, y créditos externos. El apoyo financiero del Estado incluyó al segmento de las grandes empresas en donde se desempeñaron relevantes grupos económicos.

En cuanto a la acción de la Corporación respecto a la inversión productiva, desde su creación hasta inicios de la década de los cincuenta -durante el gobierno del Partido Radical- se enfocó en la creación de filiales o grandes empresas estatales en el sector de industrias básicas encadenadas con el segmento de bienes de consumo (CORFo, 1969) ${ }^{17}$ Este proceso de acumulación fue liderado por unidades que adquirieron el carácter de monopolios públicos. Estas empresas se constituyeron como sociedades anónimas y en algunos casos recurrieron a la participación privada, siendo esta la característica del monopolio siderúrgico Compañía de Acero del Pacífico, fundada en 1943. Entre las grandes empresas creadas por el Estado se encuentran: en el sector de electricidad, la Empresa Nacional de Electricidad, en 1943; en el sector petrolero, la Empresa Nacional de Petróleo, 1950; en alimentación, la Industria Azucarera Nacional, 1952; y en el área de las telecomunicaciones, se creó en 1964 la Empresa Nacional de Telecomunicaciones. Al respecto, durante la mayor parte de la década de los cincuenta, bajo los gobiernos de Carlos Ibáñez del Campo y Jorge Alessandri Rodríguez -ambos mandatarios ubicados en centro-derecha del espectro político-, las tareas de CORFO en relación con las grandes empresas y los grupos económicos controladores de estas se inclinaron al financiamiento crediticio por encima de la formación de unidades productivas. Lo anterior, considerando especialmente la segunda mitad del gobierno de Ibáñez, con la ejecución de políticas antinflacionarias de reducción del gasto público y contención salarial. Por otra parte, en su mensaje presidencial al país en 1959, Alessandri Rodríguez determinó que "sin perjuicio

${ }^{17}$ Acerca de la historia general de CORFo, véanse Nazer (2009) y Ortega (1989). 
Aguirre, A. / El fomento crediticio a los grupos económicos en la industrialización sustitutiva de importaciones chilena (1939-1970)

de seguir desarrollándose ininterrumpidamente los programas que están en ejecución, como la electrificación del país, la CORFo no emprenderá en adelante, sin previa autorización del Gobierno, nuevas actividades que impongan desembolsos durante varios años (Alessandri, 1959, p. 42) 18

Así, en concordancia con los objetivos de la CORFo, desde la segunda mitad de la década de los cincuenta, en el contexto del alza inflacionaria y la culminación de la sustitución fácil de importaciones, el Estado chileno promovió determinados segmentos productivos que se encontraban en condiciones de satisfacer la demanda interna y disponían de ventajas comparativas con vistas a su internacionalización. Sobresalen en esta condición: la producción de papel y celulosa -junto a la actividad forestal-, y el sector pesquero. Asimismo, Alessandri (1959) señaló que "de mayor significación son las negociaciones que el Gobierno lleva adelante para obtener importantes inversiones en actividades reproductivas (sic) especialmente de exportación [...] Las industrias derivadas de nuestros bosques que deben instalarse para aumentar las exportaciones, contarán también, con la más amplia protección del Gobierno" (Alessandri, 1959, p. 34). En el caso de la pesca, el impulso sectorial se relacionó con la necesidad de activar la explotación de un recurso natural que permitió enfrentar la problemática económica y laboral generada en la zona norte del país desde mediados de la década de los cincuenta, y la oportunidad de mitigar la crisis terminal de la industria salitrera ${ }^{19}$ En la actividad pesquera, el emergente grupo Angelini se desempeñó como controlador de una de las mayores unidades del sector: Empresa Pesquera Eperva S.A. ${ }^{20}$ En la elaboración de celulosa, desde inicios de la década de los cincuenta, se planteó la factibilidad técnica de aprovechar los recursos naturales del país con vistas a la producción de esta materia prima (CEPAL, 1955, 1957). En este segmento, opera como un monopolio sectorial el grupo Matte, controlador de la Compañía Manufacturera de Papeles y Cartones (en adelante CMPC), y que desde su creación en 1959 dirige la productora de celulosa Laja. En 1967, actuando como socio mayoritario y con el objetivo de enfrentar el monopolio sectorial de la CMPC, el Estado creó plantas de explotación forestal y producción de celulosa, tal como es el caso de Arauco y Constitución.

El fomento crediticio a los grupos empresariales inició en 1953. Gran parte de los requerimientos fiduciarios para llevar a cabo el proceso inversor se sustentaron en aportaciones externas canalizadas por CORFo provenientes de organismos como el Banco Interamericano de Desarrollo, el Banco Internacional de Reconstrucción y Fomento (Banco Mundial), y el Eximbank. La

\footnotetext{
${ }^{18}$ A su vez, Sergio Molina, director general de presupuesto en los gobiernos de Ibáñez y Alessandri Rodríguez, y ministro de Hacienda del gobierno de Frei Montalva, plantea la preferencia durante el gobierno de Alessandri por concluir con la formación de empresas estatales, concentrando la acción de CoRfo en la provisión de financiamiento al sector privado (Serrano, Scantlebury, Levine y Muñoz., 1993).

${ }^{19}$ El decreto Fuerza de Ley número 208, del 3 de agosto de 1953, crea el Consejo Consultivo de Pesca y Caza, y dicta normas de fomento a las actividades pesqueras por intermedio de franquicias y exenciones tributarias. El Decreto Fuerza de Ley número 266, del 6 de abril de 1960, otorga franquicias aduaneras y tributarias a personas jurídicas que se dediquen al fomento de la actividad pesquera e industrias derivadas. Este decreto se extenderá por un máximo de trece años e incluye una reducción de $90 \%$ de la tasa o monto del impuesto a las utilidades de la empresa, como las rentas personales obtenidas. Asimismo, se considera la exención tributaria a la internación de maquinaria, equipo y embarcaciones requeridos para la actividad. Las empresas se comprometen durante un plazo de diez años a capitalizar un porcentaje no inferior a $75 \%$ de sus utilidades.

${ }^{20}$ Importante grupo económico del país en la Isı, liderado por su fundador Anacleto Angelini Fabbri a mediados de la década de los cincuenta. Este grupo controlará la mayor unidad pesquera del país: Eperva, Industrias de Oriente, la comercializadora Anagra, y la maderera Cholguán. A su vez, dispondrá de una significativa participación en el Banco Nacional del Trabajo.
} 
Aguirre, A. / El fomento crediticio a los grupos económicos en la industrialización sustitutiva de importaciones chilena (1939-1970)

provisión de créditos de largo plazo destinado a grandes unidades productivas consistió en una materia articulada según las exigencias de los prestamistas internacionales y gestionada por CORFO que actuó como aval y gestor (véase cuadro 2) 21

${ }^{21}$ Con diversas intensidades y características, el apoyo financiero al sector privado es un instrumento de la isI presente en diversos países latinoamericanos. Este es el caso de Nacional Financiera en México, con funciones de fomento a la industria desde 1940. En Argentina, el Banco de Crédito Industrial fundado en 1944. El Instituto Nacional de Industria en España llevará a cabo tareas similares en el proceso de industrialización. Sobre la banca de fomento industrial en estos países, véanse Aceña y Comín (1991), López (2012); Rougier (2007), Torre y García-Zúñiga (2013). Rougier (2011) ofrece un examen de diversos casos nacionales sobre la banca de desarrollo en América Latina. 
Aguirre, A. / El fomento crediticio a los grupos económicos en la industrialización sustitutiva de importaciones chilena (1939-1970)

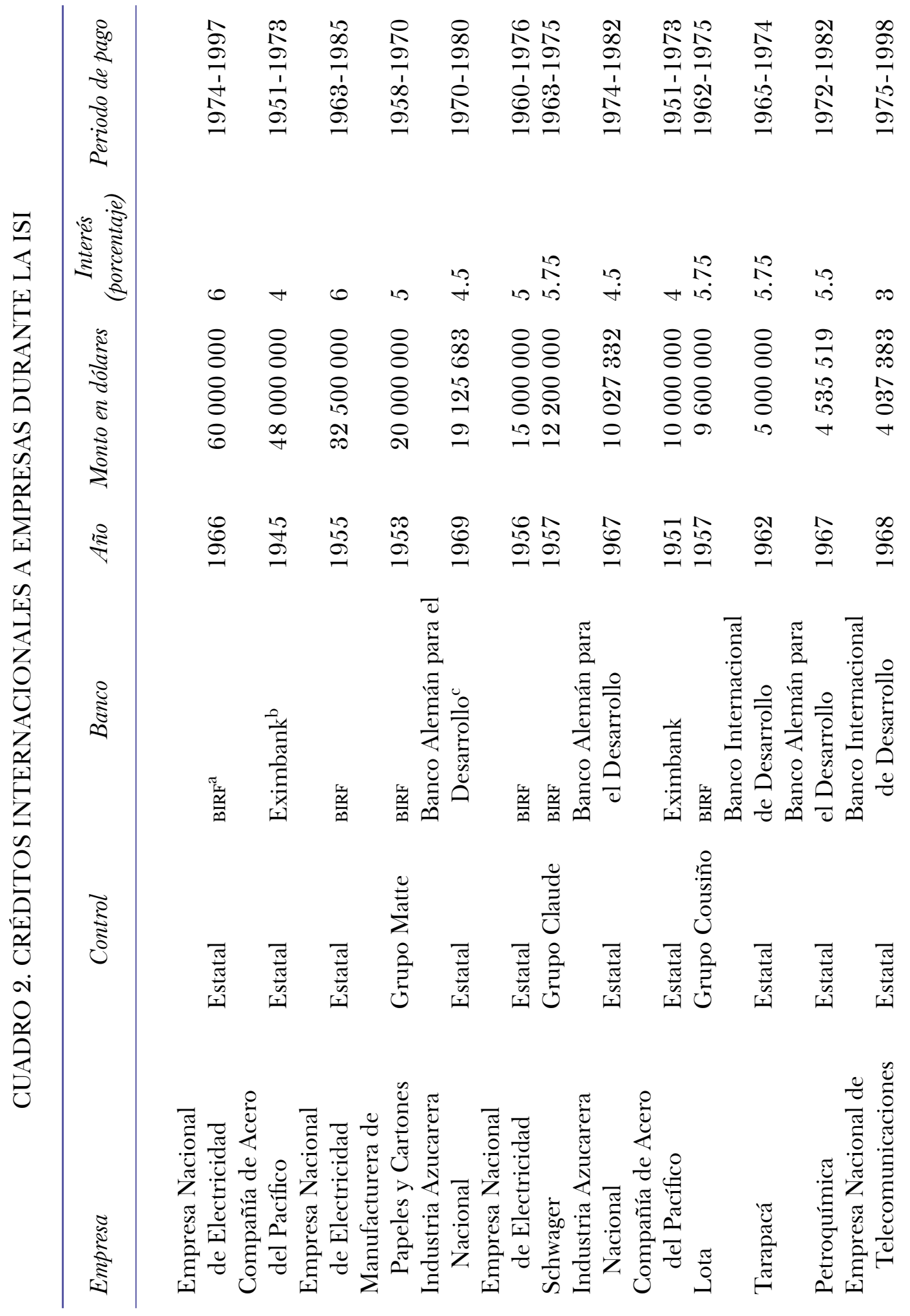


Aguirre, A. / El fomento crediticio a los grupos económicos en la industrialización sustitutiva de importaciones chilena (1939-1970)

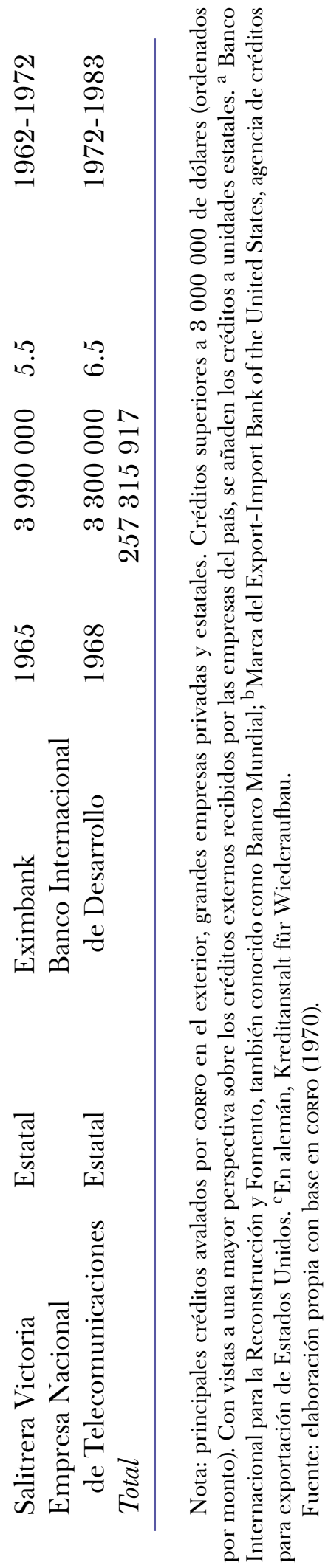


En este sentido, la Corporación tuvo plena libertad para seleccionar a los sectores y actividades receptoras del apoyo crediticio con base en sus objetivos institucionales: "La ley no determinó en forma absoluta la manera de actuar dentro del régimen crediticio, sino que se limitó en diversas disposiciones a establecer que la Corporación [de Fomento de la Producción] efectuaría ensayos de producción o comercio, o bien prestaría las ayudas que fuesen convenientes, o financiaría las obras contempladas en los planes" (CORFo, 1949, p. 5). En cuanto al financiamiento directo dispuesto por CORFO, se articuló de la siguiente forma: "aporte directo de la Corporación del capital total necesario para realizar la obra o fin correspondiente; participación de la Corporación con aporte de capital en calidad de socio o accionista de sociedades, formadas o en formación, cuya finalidad corresponda a los objetivos del plan y préstamos o créditos a terceros de acuerdo con las normas señaladas por el Consejo" (CORFO, 1949, p. 9). Para recibir los aportes de la CORFo se requirió que las personas naturales fueran $60 \%$ chilenas y que, en el caso de las personas jurídicas, en concreto las sociedades, su capital accionario fuera $60 \%$ propiedad de nacionales (Ley 6.640, 10 de enero, 1941).

Por último, bajo el principio de complementariedad respecto al sector privado que animó a la CORFo, en referencia a su participación en el control de las empresas receptoras de la ayuda, el vicepresidente ejecutivo de la CORFo entre 1939 y 1944, Guillermo del Pedregal, señaló: "La Corporación no es obstáculo para retirarse de los negocios cuando el interés particular esté en situación de substituirla con ventaja. Creo que el ideal de la Corporación sería ayudar a la formación de muchas sociedades y que, a poco caminar, pudiera retirar los capitales que aportara -pues, por mucho que sean sus recursos serán siempre escasos- para destinarlos a nuevas industrias o nuevas actividades productivas" (CORFO, 1943, p. 41) 22

En los créditos internacionales superiores a 3000 millones de dólares, el Estado chileno recibe 215515917 dólares, de los que capta $83.75 \%$ de los fondos prestados, en lo fundamental, para la formación de las grandes unidades estatales en el sector de industrias básicas y telecomunicaciones. Por tanto, $17.25 \%$ de los créditos externos contratados por la CORFo en el transcurso de la ISI se dirigieron al sector privado. Estos créditos se orientaron a tres grandes empresas nacionales controladas por grupos económicos: la CMPC del grupo Matte ${ }^{23}$ la Compañía Carbonífera y de Fundición Schwager del grupo Claude ${ }^{24}$ y la Compañía Carbonífera e Industrial de Lota del grupo Cousiño ${ }^{25}$ La envergadura de los créditos recibidos por las empresas pertenecientes a grupos económicos es de 41800000 dólares.

\footnotetext{
${ }^{22}$ Este enfoque persistirá en el transcurso de la IsI, por lo menos hasta el gobierno de la Unidad Popular iniciado a finales de 1970 (CORFO, 1966a).

${ }^{23}$ Principal grupo económico chileno durante la ISI, a la par del grupo Edwards. Formado en la segunda mitad de la década de 1920 por los hermanos Luis y Arturo Matte Larraí; además de su mayor unidad, la CMPC, Matte controló durante la ISI diversas empresas predominantes en sus respectivos mercados, como el de materiales de construcción: Pizarreño, El Volcán, Cemento Melón, la comercializadora Codina, el Banco Sudamericano, la inmobiliaria Renta Urbana, y diversas compañías de seguros.

${ }^{24}$ El grupo Claude controló a la Compañía Carbonífera y de Fundiciones Schwager, de manera conjunta con las forestales La Peña y Quiñenco previo a la fusión con Lota en 1964. En ese entonces, el grupo fue liderado por Federico Claude Schwager.

${ }^{25}$ Cousiño es un grupo empresarial creado por Matías Cousiño Jorquera a mediados del siglo xix. Dirigido por la sucesión familiar liderada por Arturo Cousiño Lyon. En el transcurso de la ISI el grupo se estructuró de forma vertical en torno a su principal empresa, la carbonífera Lota, acompañada de la naviera Arauco, Forestal Colcura, y Refractarios Lota-Green; dirigiendo además la inmobiliaria Renta Matías Cousiño. Acerca de la formación de este grupo económico y su primer siglo de actividad, véase Nazer, Llorca-Jaña y Navarrete-Montalvo (2017).
} 
Si comparamos el monto de cada crédito con el tamaño de la empresa, expresado en el capital y reservas en el año de recepción del apoyo financiero, se aprecia su relevancia. Así, obtenemos que el crédito destinado a la CMPC equivale a $175 \%$ del capital y reservas de la empresa, con un monto de 20000000 de dólares con $5 \%$ de interés anual. En el caso de la carbonífera Schwager, el crédito de 12200000 dólares con un interés de $5.75 \%$ asciende a 52 \% de sus recursos propios. Para Lota, el crédito percibido es de 9600000 dólares, alcanzando $165 \%$ del monto de capital y reservas, con una tasa de $5.75 \%$ de interés. Por tanto, la importancia de los créditos externos recibidos por estas empresas es palpable, especialmente con la CMPG - principal empresa del grupo Matte- y con Lota -unidad de mayor envergadura del grupo Cousiño-, ambas empresas predominantes en sus respectivos mercados (Gasic, 1971).

\section{LOS CRÉDITOS DISPUESTOS POR LA CORFO Y SU IMPACTO EN LOS GRUPOS ECONÓMICOS} Y LA ACTIVIDAD SECTORIAL.

Respecto a la principal empresa del grupo Matte, en consonancia con el plan de desarrollo productivo de la celulosa, el crédito gestionado por la cORFo se destinó a dos grandes proyectos de inversión: la construcción de una planta de celulosa al sulfato de 75000 toneladas anuales en Laja, región de Concepción, y la instalación de una fábrica de papel de 50000 toneladas anuales en la comuna de San Pedro, región Metropolitana (CORfo, 1957b). Hacia 1953 el proyecto Laja representó la única iniciativa empresarial del rubro de la celulosa en América Latina que recibió ayuda extranjera por parte de una institución de préstamos internacionales.

El costo de la inversión fue financiado $77.2 \%$ por las divisas del crédito externo y $23.8 \%$ por el capital propio de la empresa mediante el mecanismo de retención de utilidades y el reemplazo de la distribución de dividendos a los accionistas por títulos liberados. Como señaló Jorge Alessandri Rodríguez, presidente de la CMPG, en 1953: “[...] Esta Compañía empezará a repartir acciones liberadas con cargo a utilidades y a fondos acumulados dentro del propósito de disponer de los recursos necesarios para afrontar la construcción de las plantas de celulosa y papel de diarios que proyecta" (Manufacturera de Papeles y Cartones, 1953-1965) Esto fue autorizado mediante la reforma de los estatutos de la sociedad por el Decreto Supremo del ministerio de Hacienda número 3440, del 16 de abril de 1953, que facultó a la empresa para este efecto. El monto del capital social triplicó de manera inmediata su valor pues ascendió de 500000000 de pesos corrientes a 1 500 millones de pesos. En 1960, después de sucesivas ampliaciones de capital, el valor del capital social de la CMPC alcanzó los 12000 millones de pesos. La CMPC volverá a repartir dividendos entre sus accionistas en 196327

Según la Comisión Económica para América Latina y El Caribe (en adelante CEPAL), una de las fortalezas de este proyecto fue que corfo fungió como aval del mismo, además de su factibilidad y calidad técnica. El préstamo gestionado y avalado por la CORFO para la CMPC condujo a que en 1958, año de apertura de la planta de Laja, Chile se convirtiera en el primer exportador neto de papeles y cartones del continente, alcanzando la completa sustitución en este bien, con una

\footnotetext{
${ }^{26}$ Carta al superintendente de compañías de seguros, sociedades anónimas y bolsas de comercio, emitida por Jorge Alessandri Rodríguez, presidente de la cMPc. Referencia Técnica 23.556; 10 de junio de 1953.

2712000000 de escudos de aquel año, equivalentes a 12612000 de dólares. Sobre el plan de desarrollo de la celulosa en el país, véase cEPAL (1957).
} 
escasa importación de papel específico que asciende a $4 \%$ del consumo total 28 El respaldo crediticio consolidó la posición monopólica de la CMPC en el sector de la celulosa y papel, integrando verticalmente la elaboración de esta materia prima con su producción principal. Hasta 1958 la producción de celulosa era prácticamente inexistente en Chile, adquiriendo esta materia prima en países como Noruega, Finlandia y Estados Unidos. Entre 1950 y 1958 se producen en el país 3 475 toneladas de celulosa. Entre 1966 y 1969 se produjeron en promedio 171000 toneladas. El promedio ascendió entre 1959 y 1970 a 122400 toneladas (Stumpo, 1991) 29 De este modo, desde 1958 la CMPC se consagró como el único productor de papel de diario y pasta de celulosa en Chile, compartiendo la elaboración del rubro de otros papeles con las fábricas Pons $(3.22 \%$ de la producción) y Schorr y Concha (8\% de la elaboración). En aquel año, la empresa realizó 88.7 \% de la producción sectorial reafirmando su predominio sectorial (CEPAL, 1960, p. 22).

En el caso de los créditos otorgados a las empresas carboníferas Schwager y Lota, unidades clave en grupos empresariales integrados verticalmente en torno a este producto y que para 1956 representaron de manera conjunta más del $80 \%$ de la producción sectorial, no se obtuvieron los resultados positivos evidenciados en el caso de la CMPC (CORFO, 1957a, p. 23). El apoyo crediticio no contribuyó a superar las dificultades sectoriales caracterizadas por la competencia del petróleo, combustible con un trato preferencial en materia cambiaria, el uso creciente de la energía eléctrica, el incremento de costos y el conflicto con los sindicatos ${ }^{30}$

Respecto al crédito recibido por Schwager ${ }^{31}$ en 1957, la junta de accionistas de la empresa acordó facultar al directorio para:

contratar un préstamo con el Banco Internacional de Reconstrucción y Fomento por la suma de 8 millones de dólares americanos para el desarrollo de mecanización de la nueva mina [...] contratar con la Corporación de Fomento de la Producción el financiamiento de la moneda corriente para el objetivo indicado [...] El préstamo se podrá contratar con la garantía solidaria de la Corporación de Fomento de la Producción la que podrá figurar como codeudor directo y podrá tener la garantía del Estado de Chile 32

Con base en las negociaciones y la participación de la coRfo en la contratación del crédito, su monto final ascendió a 12200000 dólares.

La evolución de Lota, la mayor empresa del sector es buen ejemplo de las vicisitudes de la industria del carbón. Para hacer frente a la contracción del consumo interno durante la década de los cincuenta, Lota exportó parte de su producción a Argentina, comprada por unidades como Ferrocarriles Argentinos o la Usina Termoeléctrica de San Nicolás. Debido a la escasa competitividad de los precios del carbón chileno con un elevado costo de extracción por la profundidad de sus vetas y las dificultades generadas por un tipo de cambio sobrevaluado, estas ventas al exterior

${ }^{28}$ En 1950 Chile produjo 45000 toneladas de papel y cartones, e importó 20000 toneladas para satisfacer el consumo.

${ }^{29}$ Según datos del Instituto Forestal de Chile. Para una contribución sobre la evolución de la Compañía Manufacturera de Papeles y Cartones desde un enfoque industrial, véase Videla (2017).

${ }^{30}$ Sobre el consumo de carbón durante la ISI y la competencia del petróleo, véase Yáñez y Garrido (2015). En torno a la actividad reivindicativa de los obreros del carbón, véase Venegas (2011).

${ }^{31}$ Empresa controlada por el grupo Claude, que a su vez dirige diversas unidades del ámbito forestal.

32 Junta general extraordinaria de accionistas, 13 de abril de 1957, en Compañía Carbonífera y de Fundiciones Schwager (1957). 
Aguirre, A. / El fomento crediticio a los grupos económicos en la industrialización sustitutiva de importaciones chilena (1939-1970)

alcanzarán una reducida magnitud (Compañía Carbonífera e Industrial de Lota, 1957). Así, en 1952 las exportaciones de carbón efectuadas a Argentina no superarán 1.9 \% de la producción de Lota, alcanzando 32000 toneladas (Compañía Carbonífera e Industrial de Lota, 1952) ${ }^{33}$ En este contexto, la dirección de Lota declara en 1956:

Desde hace tiempo la Compañía está empeñada en una vasta campaña de opinión tendente a obtener la colaboración del Supremo Gobierno en la defensa de la Industria Carbonífera, que en los últimos años ha debido competir en condiciones desventajosas en los mercados de combustibles. Aspiramos a que se otorgue a nuestra actividad un nuevo trato al que creemos tiene derecho por su importante función dentro de la vida económica nacional 34

Según la Compañía Carbonífera e Industrial de Lota (1957), frente a la disminución de ventas en el mercado interno y con vistas a no acumular stocks, se decide por parte de los directivos de Lota una paralización de faenas de 32 días.

El origen del crédito internacional destinado a Lota se remonta a 1949, año en que se decide la mecanización de las faenas extractivas junto al desarrollo de galerías, iniciativa conocida como Plan de Mecanización y Desarrollo de la Mina ${ }^{35}$ Lo anterior detonó las negociaciones con el Banco Internacional de Reconstrucción y Fomento, las cuales se interrumpieron en 1952 "por motivos ajenos a nuestra voluntad", tal como señaló la empresa e inició con recursos propios dicha modernización. En 1957 se firmó el convenio definitivo con el que Lota obtuvo un crédito por 9 000000 de dólares, mismo documento en el que se menciona que el gobierno es: "solidario en el cumplimiento de nuestras obligaciones con el Banco Internacional. En relación con el préstamo otorgado, se autorizó por el Decreto Supremo 4870 del 27 de mayo de 1957 un aumento de capital de cuatro millones de escudos" (Compañía Carbonífera e Industrial de Lota, 1957) 36

Respecto a la producción, en 1960 descendió $29 \%$ en relación con el año anterior a raíz de la paralización de faenas de 96 días por parte de los sindicatos obreros, cuestión que coincide con la tendencia declinante de la productividad entre 1954 y 1962, considerando la recepción de la inyección de capital internacional (véase gráfica 1) ${ }^{37}$ Esta situación, junto con un persistente control de precios por parte de la autoridad, condujo a que el gobierno acordara la fusión entre los dos grandes productores carboníferos del país, de tal forma que Lota absorbió a Schwager. La finalidad de este proceso es descrita por el directorio de Lota del siguiente modo:

\footnotetext{
${ }^{33}$ Para el conjunto del sector, las exportaciones entre 1954 y 1957, alcanzaron en promedio $5.4 \%$ (Sobre exportaciones de carbón,1957).

${ }^{34}$ Compañía Carbonífera e Industrial de Lota (1956).

${ }^{35}$ Este plan de mecanización de Lota es contemporáneo con la huelga del carbón de 1947, liderada por dirigentes sindicales militantes del Partido Comunista. De importantes consecuencias políticas, esta huelga se relaciona con la denominada Ley de Defensa Permanente de la Democracia, que sancionó la ilegalidad de dicho partido político entre 1948 y 1958.

${ }^{36}$ Con los recursos captados, la empresa invirtió en: sistemas de extracción, sistemas de ventilación, generación y distribución de aire comprimido, equipo para labores en frentes de carbón, movilización, maquinaria de maestranzas y equipos varios.

${ }^{37}$ Otra medida de apoyo a la industria por parte de la autoridad consistirá en el Decreto Fuerza de Ley 255 , del 4 de abril de 1960, que establece la exención de la tributación por derechos de internación a la importación de maquinaria y equipo y cualquier otro bien destinado al mantenimiento o la operación de extracción y la exención del impuesto a la renta por un plazo de cinco años del monto de las utilidades destinadas al desarrollo de la actividad.
} 


\section{GRÁFICA 1. EXPORTACIONES DE PAPEL, PORCENTAJE SOBRE LO PRODUCIDO. CHILE, 1960-1970}

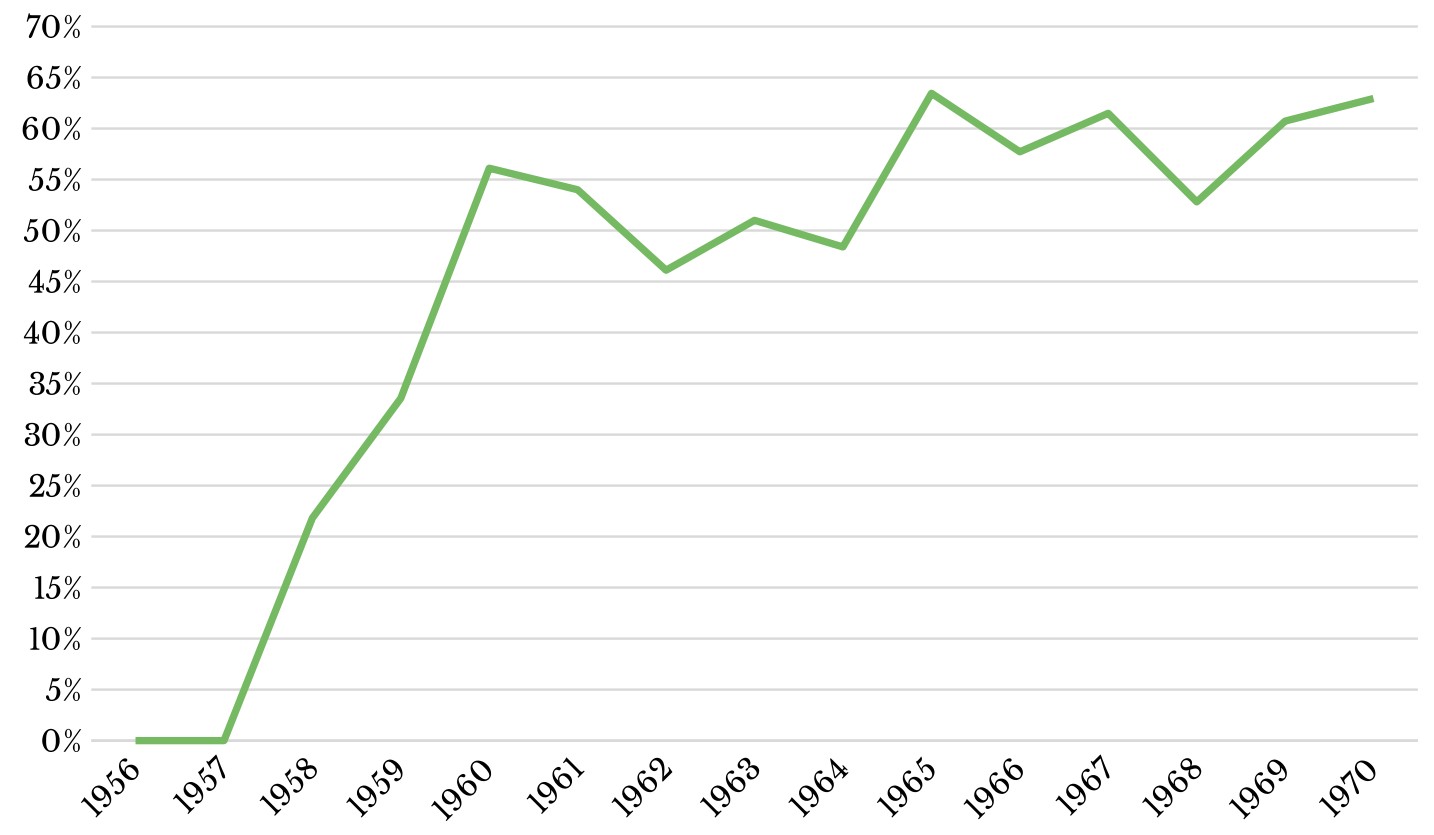

Fuentes: elaboración propia con base en Banco Central de Chile (2001) y cEPAL (1960).

[...] La fusión proyectada, según se desprende de los informes técnicos a los que se ha hecho referencia, influirá, sin duda, favorablemente sobre los costos, y se traducirá en una producción regulada de acuerdo con las necesidades del mercado. Permitirá, además, a la Compañía fusionada, actuar en el campo comercial con una mayor tranquilidad y seguridad económica, facilitándole al mismo tiempo, mayores posibilidades de obtención de créditos en condiciones financieras favorables 38

Dicha fusión se realizó con el $65 \%$ del capital perteneciente a Lota y $35 \%$ de Schwager, con un aumento de capital autorizado de Lota de 4000000 de escudos a 7200000 escudos; asimismo, el nuevo directorio de la empresa quedó conformado por seis miembros designados por Lota y tres por Schwager ${ }^{39}$ Esta centralización de capital se llevó a cabo desde el cierre del ejercicio del 31 de diciembre de 1962 formando así la Carbonífera Lota-Schwager S. A., autorizada por el decreto 64 del Ministerio de Minería del año 1963. La nueva entidad se hizo cargo de los compromisos de Schwager respecto a un crédito recibido de manera directa por la confo que ascendía a 31 823756.87 escudos, equivalente a 17018051 dólares de la época (Carbonífera Lota-Schwager, 1964-1970) ${ }^{40}$ De este modo, de manera conjunta al crédito internacional, la cobertura por parte

\footnotetext{
${ }^{38}$ Acta de la Junta General Extraordinaria de Accionistas, 15 de diciembre de 1963, en Compañía Carbonífera e Industrial de Lota (1963).

${ }^{39}$ Acta de la Asamblea General Extraordinaria de Accionistas, 26 de diciembre de 1963, en Compañía Carbonífera e Industrial de Lota (1963).

${ }^{40} \mathrm{El}$ tipo de cambio promedio en aquel año es de 1.87 escudos por dólar (Díaz, Lüders y Wagner, 2010).
} 
Aguirre, A. / El fomento crediticio a los grupos económicos en la industrialización sustitutiva de importaciones chilena (1939-1970)

de la CORFo de los costes en moneda nacional alcanzó los 16378000 dólares, divididos en 10 528788 dólares destinados a Schwager y 5849212 a Lota. El acuerdo de montos en torno a este relevante apoyo económico por parte del Estado, a través de la CORFO a las empresas carboníferas, se remonta a 1951 y su valor se calculó a un tipo de cambio promedio de 85.48 pesos por dólar de aquel año (CORFo, 1957a) ${ }^{41}$

Una de las consecuencias de esta fusión consistió en la desarticulación de los grupos empresariales Cousiño y Claude. Lota-Schwager fue controlada por el emergente grupo económico liderado por Andrónico Luksic desde 1966 42 A pesar de la visión optimista de la dirección respecto a la fusión y creación de una entidad monopólica en la industria del carbón, esta oportunidad de control pleno del mercado no posibilitó a Lota-Schwager superar la decadencia del sector (véase gráfica 2). Así, en 1966 la dirección de la empresa declaró que: “[...] la empresa atraviesa una situación económico-financiera difícil y el Directorio está preocupado de encontrar las soluciones que permitan superarla. Para ello se están adoptando serias medidas de economía en los gastos de operación e inversiones de capital" ${ }^{43}$ A su vez, la sociedad exhortó al gobierno a través de la CORFO para: "[...] aliviar la presión de las cargas financieras y mejorar los mercados para el carbón especialmente en el campo de la generación de electricidad" ${ }^{44}$ El directorio es favorable al pronto establecimiento de un segundo alto horno en Huachipato y la puesta en operación de la planta eléctrica de Bocamina. En 1968 el directorio, junto con la delicada situación de la empresa, conminó nuevamente al gobierno a la consecución de una política energética que asegurara un "mercado estable mínimo, única manera de aliviar los problemas financieros derivados de los excedentes producidos" ${ }^{45}$ Por último, en el marco del proceso de estatización y conformación del Área de Propiedad Social por parte del gobierno socialista (1970-1973), la empresa será una de las primeras unidades en pasar a la propiedad y control del Estado el 29 de diciembre de 197046

En cuanto a los resultados de créditos externos canalizados por la CORFo a las unidades controladas por grupos económicos, la trayectoria de la producción carbonífera en Chile entre 1939 y 1970 fue ascendente, considerando la participación sectorial predominante en el sector de Lota y Schwager (véase gráfica 2). Los recursos financieros destinados a los grupos Cousiño (Lota) y Claude (Schwager) no permitieron superar el declive sectorial. Por otra parte, el despegue de la producción de papel desde fines de la década de los cincuenta coincide con el crédito recibido por el grupo Matte, el cual posibilitó el inicio de actividades en las plantas de celulosa y papel a partir de 1958 (véase gráfica 3). Así, la exportación del papel se incrementa de forma sustancial, cuestión relacionada de manera estrecha con el crédito destinado a la CMPG con base en su relevante peso sectorial (véase gráfica 1). Entre 1960 y 1970 la exportación de papel creció en promedio cincuenta y seis por ciento. Por su parte, la trayectoria de la elaboración de harina de pescado desde 1957 - una de las prioridades del Estado para dinamizar la economía del norte chileno- es coincidente con los créditos internos otorgados por la CORFO a empresas pesqueras como Eperva, del

\footnotetext{
${ }^{41}$ Para el tipo de cambio promedio de 1951, véase Díaz, Lüders y Wagner (2010).

42 Acta de la Junta Ordinaria de Accionistas, 16 de julio de 1966, en Carbonífera Lota-Schwager (1964-1970).

4344a. Memoria y balance general, 31 de diciembre 1966, en Carbonífera Lota-Schwager (1964-1970).

44 44a. Memoria y balance general, 31 de diciembre 1966, en Carbonífera Lota-Schwager (1964-1970).

45 49a. Memoria y balance general, 31 de diciembre 1969, en Carbonífera Lota-Schwager (1964-1970).

4650 a. Memoria y balance general, 31 de diciembre 1970, en Carbonífera Lota-Schwager (1964-1970). Cabe señalar que en 1975 el Estado chileno integró el conjunto de las empresas que operaron en el sector carbonífero, creando así la Empresa Nacional del Carbón. Luego de décadas de estancamiento y declive de la producción, en 1997 el Estado la cerró y con ello culminó la actividad de las grandes empresas carboníferas chilenas.
} 


\section{GRÁFICA 2. PRODUCGIÓN DE CARBÓN EN GHILE, MILES DE TONELADAS (1939-1970).}

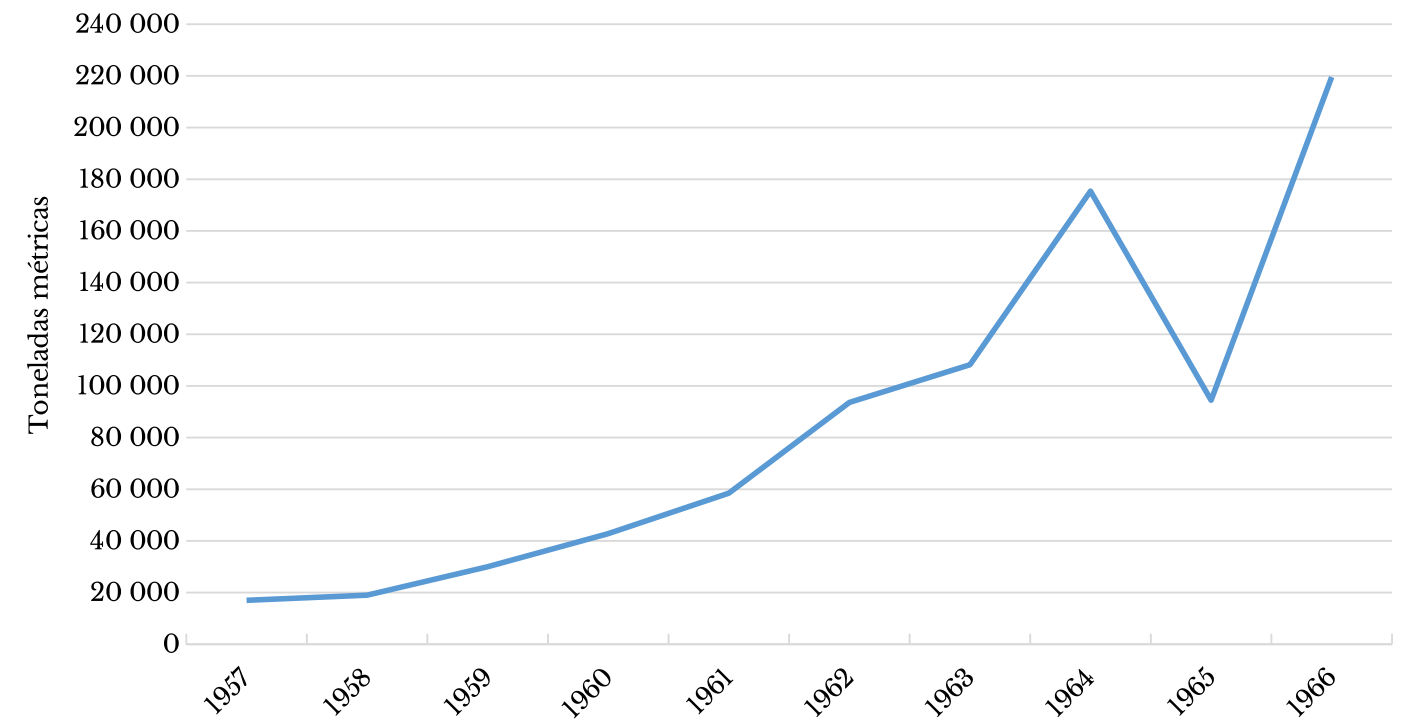

Fuentes: elaboración propia con base en Díaz, Lüders y Wagner (2010).

grupo Angelini; Industrias de Oriente (INDo), dirigida por Angelini desde la segunda mitad de la década de los sesenta; así como Pesquera Guanaye, todas ellas unidades líderes en el sector (véase gráfica 4). En 1965 el agudo descenso de la producción se relacionó con la desaparición temporal de la anchoveta, materia prima en la elaboración de harina de pescado, cuestión que generó una reorganización del tejido empresarial en favor de las mayores unidades del sector, promoviendo así la integración en unidades de gran tamaño (CORFo, 1966b). La orientación exportadora de esta actividad se verificó al contabilizar las toneladas producidas y exportadas. Por ejemplo, entre 1957 y 1961 se produjeron en el país 200747 toneladas de harina de pescado y se vendieron al exterior 102500 toneladas, equivalente a más del $50 \%$ de la producción. 47

De las 17 empresas beneficiadas por los créditos brindados por la CORFo - por encima de los 20000 dólares de cada año-, ocho de ellas son controladas por grupos empresariales al momento del crédito. El mayor monto, que supera los 10000000 de dólares, es otorgado a la empresa Schwager. Los préstamos por encima de 5000000 de dólares son otorgados a los grupos Claude y Matte; este último, después de asociarse con una empresa de origen estadunidense, constituyó la firma Laja Crown. Pizarreño, Laja Crown y la empresa pesquera Eperva, son unidades de los grupos Matte y Angelini que fueron beneficiadas de manera importante con el apoyo estatal. El $66.9 \%$ de los créditos CORFO destinados a grandes empresas privadas nacionales fueron dirigidos a grupos económicos, lo que superó los 26000000 de dólares (véase cuadro 3).

Acerca del grupo Angelini y la empresa pesquera Eperva, en 1960 se declara concluida de manera exitosa la negociación con la CORFO para la obtención de un crédito con miras a la expansión de la empresa y la creación de la nueva planta en la ciudad de Iquique, constituida por dos líneas

${ }^{47}$ Cálculos propios con base en CORFo (1962). 
GRÁFICA 3. ÍNDICE DE LA PRODUCGIÓN DE PAPEL EN CHILE (1946-1968), $1953=100$.

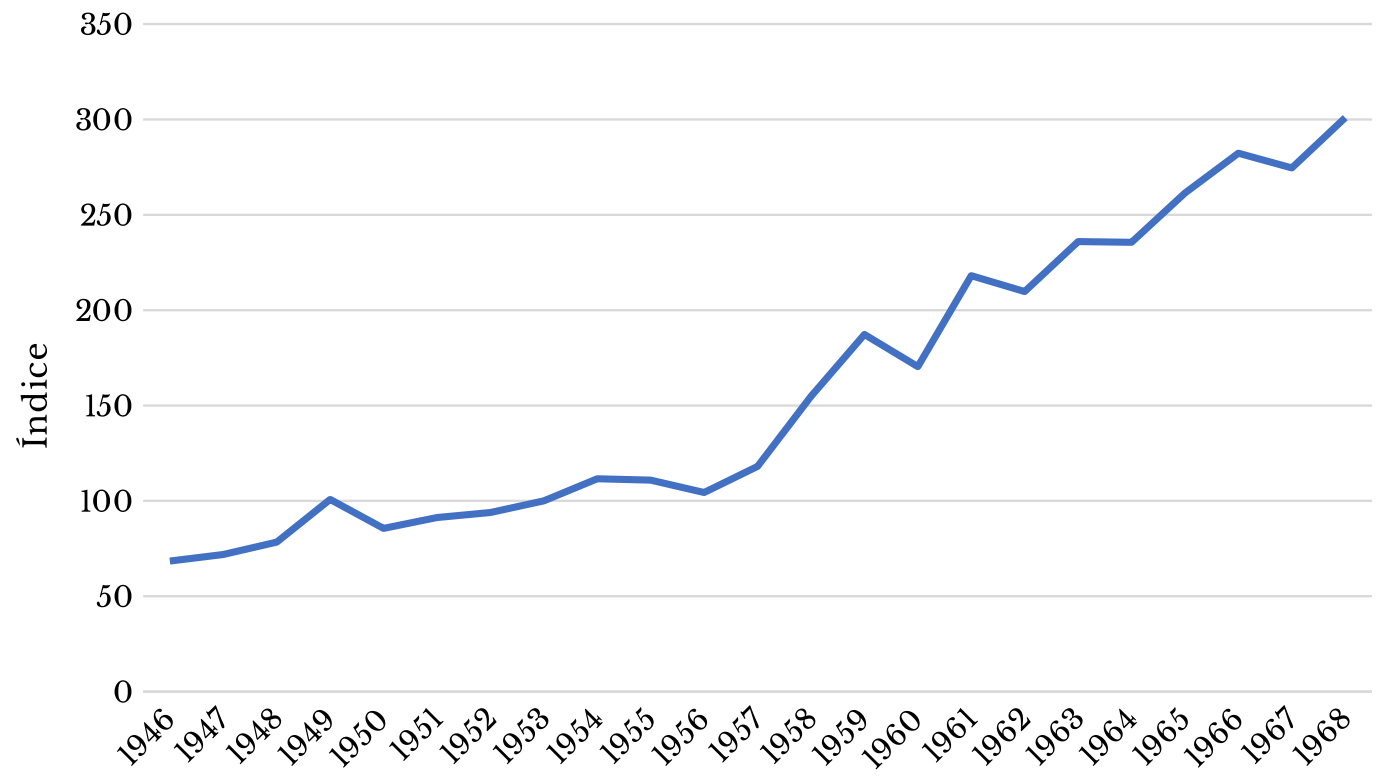

Fuentes: Nota: hasta 1959 el año base es 1936-1937-1938. Se realiza el empalme 1953=100.

Fuentes: elaboración propia con base en Chile. Dirección de Estadística y Censos (1948, 1950, 1953, 1958); Servicio Nacional de Estadística y Censos (1960, 1963); Banco Central de Chile (2001).

de producción adquiridas a la empresa danesa Sociedad Anónima Atlas. Este préstamo ascendió a 1297000 escudos, moneda de curso corriente en 1960, con una paridad uno a uno con el dólar. El préstamo es pagadero a seis años y seis meses con $6 \%$ de interés anual. El objetivo del crédito consistió en: "[...] la construcción de once barcos y en la instalación de sus líneas tres y cuatro de una planta reductora de pescado para la fabricación de harina y la obtención de aceite en el barrio industrial El Colorado de Iquique" ${ }^{48}$ A su vez, la sociedad se comprometió a no repartir dividendos en los años 1960, 1961 y 1962. El monto del crédito supuso un capital disponible para la inversión que alcanzó $62.4 \%$ de los recursos propios de la empresa 49

En resumen, el grupo Matte fue quien recibió los mayores montos en relación con créditos a grandes empresas privadas durante la IsI, ya sean nacionales o extranjeros, con 26100000 de dólares, suma de los créditos de la CMPG para Laja y Pizarreño, ambos equivalentes a $32.2 \%$ del monto total del fomento financiero al sector privado (81 034000 dólares). Le sigue el grupo carbonífero Claude a través de su empresa matriz Schwager con 22780000 dólares, 28.1 \% del total. Con base en los créditos percibidos por Lota, el grupo Cousiño recibe $19 \%$. De este modo, el conjunto del segmento carbonífero obtiene $47.1 \%$ de los créditos. Por su parte, el segmento pesquero obtendrá 3281000 de dólares, equivalente a cuatro por ciento. A inicios de la década de los setenta, Angelini pasará a controlar las principales unidades del sector. Por último, si comparamos

\footnotetext{
${ }^{48}$ Acta de la Junta general extraordinaria de accionistas, 19 de julio de 1960, en Empresa Pesquera Eperva (1960).

${ }^{49}$ El valor del capital y reservas de Eperva en 1960 es de 2075749 dólares.
} 


\section{CUADRO 3. CRÉDITOS INTERNOS A EMPRESAS DE CAPITAL PRIVADO EN EL TRANSCURSO DE LA ISI, 1941-1968}

\begin{tabular}{|c|c|c|c|c|}
\hline Empresa & Sector & $\begin{array}{c}\text { Control al momento } \\
\text { del crédito }\end{array}$ & Año & $\begin{array}{l}\text { Crédito en miles } \\
\text { de dólares }\end{array}$ \\
\hline Schwager & Carbonífero & Grupo Claude & 1957 & 10528 \\
\hline Lota & Carbonífero & Grupo Cousiño & 1957 & 5850 \\
\hline Industria Azucarera & & & & \\
\hline Nacional (iansa) & Azúcar & Mixto & 1941 & 5500 \\
\hline Laja Crown & Celulosa & Grupo Matte & 1962 & 5470 \\
\hline $\begin{array}{l}\text { Manufacturas de Cobre } \\
\text { (Madeco) }\end{array}$ & Metalurgia & Privado & 1958 & 3000 \\
\hline Bío-Bío & Cemento & Grupo Briones & 1962 & 1500 \\
\hline Empresa Pesquera Eperva & Pesca & Grupo Angelini & 1962 & 1297 \\
\hline $\begin{array}{l}\text { Industrias de Oriente } \\
\text { (Indo) }\end{array}$ & Pesca & Privado & 1962 & 1000 \\
\hline Cholguán & Madera & Privado & s. d. & 870 \\
\hline $\begin{array}{l}\text { Manufacturas de Cobre } \\
\text { (Madeco) }\end{array}$ & Metalurgia & Mixto & 1944 & 700 \\
\hline Cemento Melón & Cemento & Privado & 1948 & 700 \\
\hline Indus & Pesca & Grupo Edwards & s. d. & 660 \\
\hline Masisa & $\begin{array}{l}\text { Madera } \\
\text { Materiales }\end{array}$ & Privado & s. d. & 650 \\
\hline Pizarreño & construcción & Grupo Matte & s. d. & 630 \\
\hline Cementera Polpaico & Cemento & Grupo Gildemeister & 1954 & 355 \\
\hline Guanaye & Pesca & Privado & 1962 & 324 \\
\hline $\begin{array}{l}\text { Manufactura de Metales } \\
\text { (Mademsa) } \\
\text { Total }\end{array}$ & Electrodomésticos & Mixto & 1941 & $\begin{array}{r}200 \\
39234\end{array}$ \\
\hline
\end{tabular}

Fuente: elaboración propia con base en Chile. Senado de la República (1972); corfo (1969). 


\section{GRÁFICA 4. PRODUCGIÓN DE HARINA DE PESCADO EN CHILE (1957-1966), TONELADAS MÉTRICAS.}

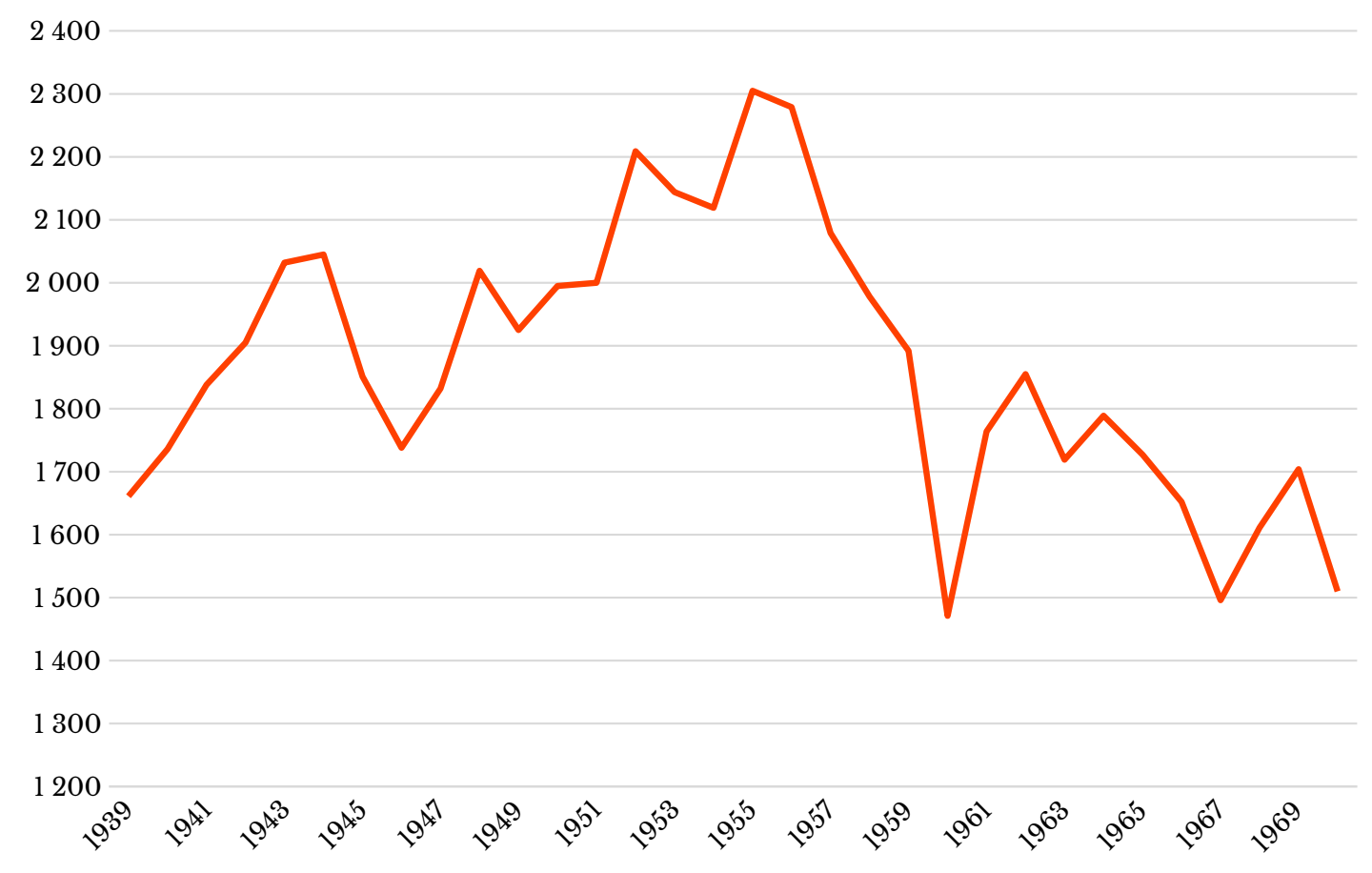

Fuentes: elaboración propia con base en Banco Central de Chile (2001); corfo (1962).

el monto de los créditos dirigidos a las grandes unidades controladas por grupos económicos y el recibido por el Estado en su papel empresarial, los grupos captan 69960000 de dólares, representando $32.4 \%$ de los créditos internacionales recibidos por CORFO para la conformación de empresas estatales. El porcentaje sobre el total del crédito de largo plazo para el sector privado de grandes empresas individuales o afiliadas a grupos económicos alcanzó $27.3 \%$. En suma, los créditos externos canalizados por la CORFo contribuyeron a posicionar a Matte como el principal grupo económico del país durante la ISI, desde la segunda mitad de la década de los cincuenta, por encima del grupo Edwards, e impulsaron a Angelini a situarse entre los mayores grupos chilenos en la década de los sesenta.

Por otra parte, y como se ha mencionado anteriormente, en el transcurso de los gobiernos de Carlos Ibáñez del Campo -de 1952 a 1958- y Jorge Alessandri Rodríguez -de 1958 a 1964-, CORFO centró su acción en el desempeño de tareas crediticias deteniéndose la política de creación de empresas por parte del Estado, impulso recuperado en 1964 con la creación de Empresa Nacional de Telecomunicaciones en los inicios del mandato de Eduardo Frei Montalva. En este escenario, resaltan las vinculaciones entre los grupos empresariales receptores del apoyo financiero y el marco político-institucional. Este es el caso distintivo de Matte, grupo económico fundado por Luis Matte, secundado por su hermano Arturo Matte Larraín, senador de la República entre 1947 y 1949 , ministro de Hacienda del gobierno de Juan Antonio Ríos entre 1943 y 1944, y candidato a la presidencia del país en 1952. Arturo Matte, fue yerno de Arturo Alessandri Palma, representante del 
partido liberal, primer mandatario de la República en dos periodos: 1920-1925 y 1932-1938. En la CMPC, Jorge Alessandri Rodríguez, hijo de Alessandri Palma, se desempeñó como su presidente de la CMPC entre 1939 y 1957, así como mandatario de la República entre 1958 y 1964, apoyado por una alianza liberal-conservadora y por el Partido Radical en la primera mitad de su mandato (Figueroa, 1925; Valencia, 1986). ${ }^{50}$

Respecto al grupo Angelini, y en general para el segmento pesquero, es también posible establecer vínculos con el entorno político-institucional. En Eperva, principal unidad del grupo Angelini durante la ISI, se desempeñó desde la fundación de la compañía como accionista, subgerente administrativo, gerente general y presidente de la misma, Felipe Zaldívar Larraín, hermano de Andrés Zaldívar Larraín, ministro de Hacienda del Gobierno del demócrata-cristiano Eduardo Frei Montalva entre 1968 y 1970, y senador de la República por tres periodos posteriores a la recuperación de la democracia política en 1990. La empresa INDo fue presidida por Salvador Pubill, tesorero de la campaña presidencial de Eduardo Frei Montalva, hasta que el grupo Angelini tomó su control. A su vez, Guanaye fue creada y controlada por Edmundo Pérez, ministro de Obras Públicas entre 1965 y1967, y ministro del Interior de 1968 a 1969, también durante el gobierno de Frei Montalva (Chile. Senado de la República, 1991; Empresa Pesquera Eperva, 1955-1970).

En relación con el grupo económico Cousiño y en concreto su principal empresa, la carbonífera Lota, sobresalen los lazos de parentesco entre el subgerente, gerente general y director de la compañía por más de cuatro décadas hasta 1965, Guillermo Videla Lira, hermano del destacado político liberal Hernán Videla Lira, senador de la República de 1941 a 1965 y embajador de Chile en Argentina entre 1965 y 1973 . Hernán Videla Lira se desempeñó además como presidente de la Sociedad Nacional de Minería, organismo que agrupó a los grandes productores mineros del país entre 1937 y 1965 (Biblioteca del Congreso Nacional de la República de Chile, s. f.).

\section{Conclusiones}

Hemos examinado que, en el transcurso de la isi, en un contexto de languidez del mercado bursátil y dificultades para el crédito de largo plazo, el financiamiento de importantes proyectos de inversión de grupos económicos y grandes empresas se sustentó en el crédito internacional y en el apoyo doméstico brindado por la corfo. Para la provisión de los préstamos externos, el Estado chileno, a través de la Corporación de Fomento, gestionó los recursos provenientes de entidades multilaterales con sede en Estados Unidos y de bancos de desarrollo internacionales. Esta inversión extranjera indirecta canalizada por el Estado se dirigió a unidades clave entre los principales grupos económicos del periodo: la CMPC, propiedad del grupo Matte; la Compañía Carbonífera e Industrial de Lota, perteneciente al grupo Cousiño; y la Compañía Carbonífera y de Fundiciones Schwager, dirigida por el grupo Claude. En estos créditos, la corfo se desempeñó como aval y copartícipe en la gestión del mismo. En relación con los créditos nacionales, estos actuaron como complemento a los préstamos externos para el caso de la CMPC y las carboníferas Lota y Schwager. También destaca en el conjunto de créditos financiados por la Corporación el apoyo brindado al grupo Angelini y a diversas unidades que operan en el segmento pesquero.

\footnotetext{
${ }^{50}$ Sobre las relaciones entre los grupos económicos y el Estado desde un enfoque de redes de directores interempresas, véase Salvaj y Couyoumdjian (2016). Sobre las vinculaciones entre el Estado y el sector privado durante la ISI, véanse Montero (1997) y Zeitlin y Ratcliff (1988).
} 
El conjunto de los créditos destinados por la CORFo a los grupos empresariales se llevó a cabo en el marco de las complejidades suscitadas por la saturación de la etapa de sustitución fácil de importaciones en los mercados industriales domésticos y consideró a los gobiernos situados en centro-derecha del espectro político.

El resultado del empleo de los créditos fue dispar. En el caso de la gran unidad papelera del grupo Matte, el apoyo financiero consolidó su posición sectorial y de mercado, convirtiéndose así en el único productor de celulosa en Chile. Con base en los recursos recibidos, la principal empresa del grupo, Compañía Manufacturera de Papeles y Cartones, dispuso del capital fijo necesario para iniciar su expansión en el mercado externo. En relación con las empresas carboníferas, la abundante inyección de recursos externos e internos no permitió reimpulsar la producción reflejando la irremontable crisis sectorial. El crédito interno al grupo Angelini contribuyó de manera significativa a expandir su actividad consolidando su posición en la rama pesquera, segmento fomentado por el Estado con un claro perfil exportador. Cabe añadir que, considerando a las exportaciones no tradicionales de papel, celulosa y harina de pescado, el fomento crediticio estatal otorgado a través de la CORFo durante la ISI, contribuyó de manera decisiva al auge exportador registrado desde la segunda mitad de la década de 1980, en el marco del sistema económico de mercado.

Los créditos se deslindaron de los rubros en donde se desempeñaban algunos de los mayores grupos económicos del país vinculados al mercado interno con un amplio nivel de sustitución de importaciones, por ejemplo, en el segmento textil con Yarur y Said, o en el sector de alimentos con Edwards.

Por último, las vinculaciones o redes por intermedio de lazos partidarios o de parentesco entre el gran empresariado partícipe de los créditos canalizados por la CORFo y la esfera políticoinstitucional es una interesante vía de análisis para el estudio del espacio de relaciones públicoprivado en el proceso de industrialización y el carácter clientelar del capitalismo chileno a largo plazo.

\section{REFERENCIAS}

Aceña, P. M., y Comín, F. (1991). INI: 50 años de industrialización en España. Madrid: Espasa Calpe.

Aguirre, A. (2017). Los grupos económicos chilenos en perspectiva histórica: entre la industrialización sustitutiva de importaciones y el neoliberalismo (1938-1988) (Tesis de doctorado). Universitat de Barcelona, España.

Alessandri, J. (1935, 1959). Mensaje presidencial. Santiago de Chile: Gobierno de Chile.

Amsden, A. H. (2001). The rise of "the rest":challenges to the west from late-industrializing economies. Oxford: Oxford University Press.

Banco Central de Chile (2001). Indicadores económicos y sociales de Chile: 1960-2000. Chile: Autor. Bértola, L., y Ocampo, J. A. (2013). El desarrollo económico de América Latina desde la independencia. México: Fondo de Cultura Económica.

Bethell, L. (ed.) (1994). The Cambridge history of Latin America. Cambridge: Cambridge University Press.

Biblioteca del Congreso Nacional de la República de Chile (s. f). Reseñas parlamentarias. Recuperado de https://www.bcn.cl/historiapolitica/resenas_parlamentarias/wiki/Hern \%C3\%A1n_Videla_Lira

Bulmer-Thomas, V. (ed.). (1998). La historia económica de América Latina desde la independencia. México: Fondo de Cultura Económica. 
Carbonífera Lota-Schwager. (1964-1970). Memorias y balances. Santiago de Chile: Autor.

Casanova, M. (2018). Los orígenes del desarrollismo económico en Chile (1932-1945): ¿Estado empresario o empresarios en el Estado? (Tesis de doctorado) Freie Universität Berlin, Alemania. DoI: 10.17169/REFUBIUM-210

Cavarozzi, M. (2017). Los sótanos de la democracia chilena, 1938-1964: las esferas de "protección" de los empresarios industriales: la CORFo, represión a los obreros y la inflación. Santiago: LOM Ediciones/Universidad de Santiago de Chile.

Chile. Dirección de Estadística y Censos. (1948). Anuario estadístico [años 1948, 1950, 1953, 1958]. Santiago de Chile: Autor.

Chile. Senado de la República (1972). Diario de sesiones: Legislatura ordinaria. Santiago de Chile: Autor.

Chile. Senado de la República (1991). Diario de sesiones: Legislatura ordinaria 332. Santiago de Chile: Autor.

Comisión Económica para América Latina y el Caribe [CEPAL] (ed.) (1955). Perspectivas de la industria de papel y celulosa en América Latina. Santiago de Chile: Autor.

Comisión Económica para América Latina y El Caribe [CEPAL] (ed.) (1957). Chile, potential pulp and paper exporter. Santiago de Chile: Autor.

Comisión Económica para América Latina y El Caribe [CEPAL] (ed.) (1960). La industria del papel y la celulosa en América Latina. Santiago de Chile: Autor.

Compañía Carbonífera e Industrial de Lota (1952). Memoria legal. Santiago de Chile: Autor.

Compañía Carbonífera e Industrial de Lota $(1956,1963,1957)$. Memorias y balances. Santiago de Chile: Autor.

Compañía Carbonífera y de Fundiciones Schwager (1957). Memoria legal. Santiago de Chile: Autor.

Corporación de Fomento de la Producción [CORfo] (1939). Plan de fomento industrial. Santiago de Chile: Imprenta y Litografía Universo.

Corporación de Fomento de la Producción [CORFo] (1943). Cinco años de labor 1939-1943. Santiago de Chile: Autor.

Corporación de Fomento de la Producción [CORFo] (1949). Diez años de labor 1939-1949. Santiago de Chile: Autor.

Corporación de Fomento de la Producción [CORFo] (1954). Quince años de labor 1940-1954. Santiago de Chile: Autor.

Corporación de Fomento de la Producción [CORfo] (1957a). Cuentas nacionales 1940-1954. Santiago de Chile: Autor.

Corporación de Fomento de la Producción [CORFo] (1957b). Labor realizada entre los años 1952 y 1956. Santiago de Chile: Autor.

Corporación de Fomento de la Producción [CORfo] (1962). Geografía económica de Chile. Santiago de Chile: Talleres Gráficos La Nación.

Corporación de Fomento de la Producción [CORFo] (1966a). Anuario de filiales y consultas. Santiago de Chile: Gerencia de Filiales.

Corporación de Fomento de la Producción [CORfo] (1966b). El desarrollo industrial de Chile. Santiago de Chile: Autor.

Corporación de Fomento de la Producción [CORFo] (1969). 30 años de CORFo, 1939-1969. Santiago de Chile: Autor. 
Corporación de Fomento de la Producción [CORFo] (1970). Financiamiento externo, Gerencia de Promoción Financiera. Santiago de Chile: Departamento de Créditos Externos.

Díaz, J., Lüders, R. y Wagner, G. (2010). La república en cifras: estadísticas históricas. Santiago de Chile: Pontifica Universidad Católica de Chile.

Díaz, J., Lüders, R. y Wagner, G. (2016). Chile 1810-2010: la república en cifras: estadísticas históricas. Santiago de Chile: Ediciones Universidad Católica de Chile.

Diaz-Alejandro, C. (1985). Good-bye financial repression, hello financial crash. Journal of Development Economics, 19(1-2), pp. 1-24. DOI: 10.1016/0304-3878(85)90036-7

Empresa Pesquera Eperva. (1955, 1960). Memorias y balances. Santiago de Chile: Autor.

Fajnzylber, F. (1983). La industrialización trunca de América Latina. México: Centro de Economía Transnacional/Nueva Imagen.

Fernández, P., Lluch, A. y Barbero, M. I. (eds.) (2015). Familias empresarias y grandes empresas familiares en América Latina y España: una visión de largo plazo. Bilbao: Fundación BBVA.

Ffrench-Davis, R. (2008). Chile entre el neoliberalismo y el crecimiento con equidad: Reformas y políticas económicas desde 1973. Chile: L. C. Sáenz.

Figueroa, V. (1925). Diccionario histórico biográfico y bibliográfico de Chile. Santiago de Chile: Imprenta y Litografía La Ilustración.

Garretón, O. G. y Cisternas, J. (1970). Algunas características del proceso de toma de decisiones en la gran empresa chilena: La dinámica de la concentración. Santiago de Chile: Corporación de Fomento de la Producción.

Gasic, G. (1971). Concentración, entrelazamiento y descentralización en la industria manufacturera. Santiago de Chile: Universidad de Chile.

Haggard, S. (1990). Pathways from the periphery: the politics of growth in the newly industrializing countries. Ithaca: Cornell University Press.

Hirschman, A. O. (1981). La estrategia del desarrollo económico. México: Fondo de Cultura Económica.

Hofman, A. A. (2000). The economic development of Latin America in the twentieth century. Northampton: Edward Elgar.

Ibáñez, A. (1994). El liderazgo de los gremios empresariales y su contribución al desarrollo del Estado Moderno durante la década del treinta: el fomento a la producción y los antecedentes de CORFo. Historia, 28, 183-216.

Instituto de Organización y Administración de Empresas. (1962). El financiamiento de la industria en Chile. Santiago de Chile: Universidad de Chile.

Jaramillo, R., Müller, W., Izquierdo, V. y Simón, R. (1939). El concepto de industria nacional y la protección del Estado. Revista Anales, 6.

Jeftanovic, P. (1961). Investigación sobre el impacto de la inflación en las utilidades bancarias. Santiago de Chile: Universidad Católica de Chile.

Jeftanovic, P. (1979). El mercado de capitales en Chile. Santiago de Chile: Universidad Católica de Chile.

Jones, G. G. y Lluch, A. (2011). El impacto histórico de la globalización en Argentina y Chile: Empresas y empresarios. Buenos Aires: Temas Grupo Editorial.

Kindleberger, Ch. P. (1992). El orden económico internacional: ensayos sobre las crisis financieras y los servicios públicos internacionales. Barcelona: Crítica.

Kirsch, H. W. (1977). Industrial development in a traditional society: the conflict of entrepreneurship and modernization in Chile. Gainesville: University Press of Florida. 
Aguirre, A. / El fomento crediticio a los grupos económicos en la industrialización sustitutiva de importaciones

Lagos, R. (1960). La concentración del poder económico: su teoría, y realidad chilena. Santiago de Chile: Del Pacífico.

Landerretche, O. (1983). Inflation and socio-political conflict in Chile, 1955-1970 (Tesis de doctorado). University of Oxford, Reino Unido.

López, P. J. (2012). El papel de Nacional Financiera durante la industrialización vía sustitución de importaciones en México. América Latina en la Historia Económica, 19(3), p. 129. Dor: 10.18232/alhe.v $19 \mathrm{i} 3.531$

Mamalakis, M. (1976). The growth and structure of the Chilean economy: from independence to Allende. New Haven: Yale University Press.

Manufacturera de Papeles y Cartones. (1953-1965). Memorias y balances. Santiago de Chile: Autor.

Marichal, C. (2010). Nueva historia de las grandes crisis financieras. Una perspectiva global, 1873-2008. Barcelona: Debate.

McKinnon, R. (1980). Financial policies. En J. Cody, H. Hughes y D. Wall (eds.), Policies for industrial progress in developing countries (pp. 93-120). Nueva York: Oxford University Press.

Meller, P. (2007). Un siglo de economía política chilena (1890-1990). Santiago de Chile: Andrés Bello.

Montero, C. (1997). La revolución empresarial chilena. Santiago: Corporación de Estudios para Latinoamérica/Dolmen Ediciones.

Muñoz, O. (1968). Crecimiento industrial de Chile, 1914-1965. Santiago: Universidad de Chile.

Muñoz, O. (1995). Los inesperados caminos de la modernización económica. Santiago de Chile: Universidad de Santiago de Chile.

Nazer, J. R., Llorca-Jaña, J. y Navarrete-Montalvo, M. (2017). The Cousiño-Goyenechea family, 1810-1940: A big Chilean family business. Atenea, 516, 49-67.

Nazer, R. (2009). Corporación de fomento a la producción y la modernización económica de Chile. 19391970. Santiago de Chile: Universidad de Santiago de Chile.

Ocampo, J. A., Cárdenas, E. y Thorp, R. (eds.) (2003). Industrialización y Estado en la América Latina: La leyenda negra de la posguerra. México: Fondo de Cultura Económica.

Ortega, L. (1989). Corporación de Fomento de la Producción: 50 años de realizaciones, 1939-1989. Santiago de Chile: Universidad de Santiago de Chile.

Paredes, R. y Sánchez, J. (1996). Organización industrial y grupos económicos: el caso de Chile. Santiago de Chile: Universidad de Santiago de Chile.

Pinto, A. (1959). Chile, un caso de desarrollo frustrado. Santiago de Chile: Universitaria.

Pinto, A. (1964). Chile, una economía difícil. México: Fondo de Cultura Económica.

Pinto, A. (1986). Estado y empresa privada, una visión retrospectiva de la experiencia chilena. El Trimestre Económico, 53(209), 105-148.

Prados, J. (1956). Inflación y desarrollo económico. Madrid: Aguilar.

Prebisch, R. (1981). Capitalismo periférico: Crisis y transformación. México: Fondo de Cultura Económica.

Reinhart, C. y Rogoff, K. (2011). Esta vez es distinto: ocho siglos de necedad financiera. Madrid: Fondo de Cultura Económica.

Rougier, M. (2007). Crédito e industria en tiempos de Perón, 1944-1955. Historia Industrial, 16, pp. $79-113$.

Rougier, M. (2011). La banca de desarrollo en América Latina: Luces y sombras en la industrialización de la región. Buenos Aires: Fondo de Cultura Económica. 
Sobre exportaciones de carbón (1957) Boletín Minero de la Sociedad Nacional de Minería, 67(650), pp. 3339-3395.

Salvaj, E. y Couyoumdjian, J. P. (2016). 'Interlocked' business groups and the state in Chile (1970-2010). Business History, 58(1), pp. 129-148. Dor: 10.1080/00076791.2015.1044517

Serrano, M., Scantlebury, M., Levine, F. y Muñoz, O. (1993). Historias personales, políticas públicas: entrevistas de Margarita Serrano y Marcia Scantlebury. Santiago de Chile: Los Andes.

Servicio Nacional de Estadística y Censos. (1960). Estadística chilena [años 1960, 1963]. Santiago de Chile: Autor.

Silva, E. (2007). The Import-Substitution Model: Chile in Comparative Perspective. Latin American Perspectives, 34(3), 67-90. DoI: 10.1177/0094582X07300589

Sociedad de Fomento Fabril (1963). Qué es la industria chilena. Santiago de Chile: Autor.

Stumpo, G. (1991). Sector del papel y la celulosa en Chile. Chile: Comisión Económica para América Latina y el Caribe.

Sunkel, O. (2011). El presente como historia: dos siglos de cambio y frustración en Chile. Santiago de Chile: Catalonia.

Torre, J. y García-Zúñiga, M. (2013). El impacto a largo plazo de la política industrial del desarrollismo español. Investigaciones de Historia Económica, 9(1), 43-53. Dor: 10.1016/j.ihe.2012.09.001

Valencia, L. (1986). Anales de la república. Santiago de Chile: Andrés Bello.

Venegas, H. (2011). De imprescindibles a marginados. Las movilizaciones de los trabajadores del carbón en Chile a mediados del siglo xx. Tiempo Histórico, 3, 105-126.

Videla, E. (2017). Compañía Manufacturera de Papeles y Cartones: Fomento Estatal y Emprendimiento Empresarial en el surgimiento de una industria monopólica, 1920-1973. En M. Llorca-Jaña y D. Barría (eds.), Empresas y empresarios en la historia de Chile, 1930-2015 (pp. 133182). Santiago de Chile: Universitaria.

Yáñez, C. y Garrido, M. (2015). El consumo de carbón en Chile entre 1933-1960. Transición energética y cambio estructural. Revista Uruguaya de Historia Económica, 5(8), 76-95.

Zeitlin, M. y Ratcliff, R. (1988). Landlords and capitalists: The dominant class of Chile. Princeton: Princeton University Press. 